\title{
PENDETEKSIAN SINAR KOSMIK MENGGUNAKAN SENSOR CMOS PADA PERANGKAT WEBCAM KOMERSIL
}

\author{
NOWO RIVELI *, LIU KIN MEN, RAFIF TRI BAIHAQI \\ Departemen Fisika, FMIPA, Universitas Padjadjaran \\ Jl. Raya Bandung-Sumedang Km.21 Jatinangor 45363, Sumedang, Jawa Barat \\ *email :nowo@phys.unpad.ac.id
}

\begin{abstract}
Abstrak. Sensor CMOS yang terdapat pada perangkat kamera digital komersil dapat dimanfaatkan sebagai alat pendeteksi partikel elementer. Di dalam penelitian ini telah dilakukan pendeteksian sinar kosmik pada permukaan bumi menggunakan webcam Logitech 260 yang dimodifikasi. Data - data berupa noise serta jenis - jenis jejak gambar yang diakibatkan partikel kosmik telah diperoleh. Histogram nilai intensitas gambar dari jejak partikel menunjukkan penurunan dengan bertambahnya intensitas, mirip dengan perilaku spektrum energi. Serta diperoleh nilai fluks kejadian sinar kosmik di permukaan bumi sebesar $1,4 \frac{\text { kejadian }}{\text { menit } \cdot \mathrm{cm}^{2}}$.
\end{abstract}

Kata kunci : sinar kosmik, CMOS, webcam, spektrum energi

\begin{abstract}
CMOS censor inside commercial digital camera devices can be used as an elementary particle detector. In this work the detection of cosmic rays has been performed using a modified Logitech 260 webcam. Data in the form of noise as well as types of images left by cosmic particles are obtained. The histogram of particle track image intensity is decreasing as the intensity increases, more like the behavior of the energy spectrum of cosmic rays.
\end{abstract}

Keywords : cosmic ray, CMOS, webcam, energy spectrum

\section{Pendahuluan}

Sinar kosmik adalah salah satu sumber alamiah dari radiasi partikel yang ada di lingkungan, selain dari bahan - bahan radioaktif yang ada baik di permukaan maupun di dalam tanah. Asal - usul dari sinar kosmik sendiri sampai saat ini masih menjadi bahan kajian di bidang fisika partikel teoritik maupun astrofisika [1]. Sinar kosmik umumnya berupa partikel bermuatan, utamanya proton, dengan rentang energi yang sangat luas, dari $10^{0}$ hingga $10^{20}$ elektronVolt [2].

Sinar kosmik yang mencapai permukaan bumi didominasi oleh partikel muon, sebagai produk interaksi proton kosmik dengan materi dalam atmosfer bumi. Muon dapat mencapai ke permukaan bumi diantaranya karena energi yang tinggi, waktu hidup yang mencukupi, serta sifatnya yang sulit dihentikan oleh material penghalang. Pendeteksian muon kosmik pada permukaan bumi telah banyak dilakukan untuk berbagai aplikasi. Baik untuk penyelidikan sinar kosmik itu sendiri, maupun salah satunya untuk tomografi objek - objek besar.

Teknologi yang digunakan dalam pendeteksian partikel umumnya tua, mahal dan sulit diperoleh. Sebagai contoh, detektor partikel berjenis kalorimeter (pengukuran energi), menggunakan bahan sintilator dan peralatan Photomultiplier yang harus dioperasikan dengan tegangan tinggi. Dua hal tersebut sulit ditemukan di Indonesia. 
Sebagai alternatif, saat ini terdapat teknologi - teknologi komersil yang dapat dimanfaatkan untuk pendeteksian partikel elementer, salah satunya sensor CMOS yang terdapat dalam webcam.

Potensi penggunaan kamera digital komersil telah mulai dipelajari dalam pemanfaatannya untuk pengukuran material sub atomik, seperti pada [3]. Telah diperoleh bahwa jenis partikel yang melewati sensor dapat dikenali (sebagian) dengan melihat bentuk gambar yang tertinggal pada kamera [4]. Metode pengukuran sinar kosmik dengan kamera digital komersil telah diinkorporasikan dalam bentuk aplikasi peralatan telepon pintar, sehingga pengukuran sinar kosmik dapat dilakukan oleh banyak warga di berbagai tempat $[5,6]$. Pengukuran menggunakan kamera digital juga telah digunakan untuk mengidentifikasi dan klasifikasi jenis partikel yang melewatinya [7].

Sensor kamera digital terbuat dari alat Complimentary Metal Oxide Semiconductor (CMOS). Sensor CMOS tersebut tersusun dari jutaan piksel fotodioda silikon. Penggunaan utama dari sensor CMOS adalah mendeteksi foton cahaya tampak pada energi beberapa $\mathrm{eV}$. Cahaya tampak memasuki bidang sensor akan mengionisasi elektron pada lapisan deplesi melalui interaksi fotolistrik. Elektron bebas serta hole yang tercipta akan menghasilkan arus mikroskopis, rangkaian pada perangkat webcam akan memperkuat serta mendigitalisasi arus mikro tersebut. Untuk webcam komersil, besaran yang dikirimkan ke komputer dengan kabel USB adalah nilai intensitas tidak bersatuan dengan rentang 0-255. Besaran nilai intensitas tersebut sebanding dengan jumlah muatan bebas yang terkumpulkan.

Prinsip yang sama juga terjadi ketika terapat partikel elementer yang melewati sensor. Untuk partikel kosmik dengan energi sekitar $10 \mathrm{MeV}$, interaksi yang dominan adalah hamburan Compton dan pair-production, namun dengan hasil yang sama yaitu terciptanya pasangan elektron-hole bebas yang akhirnya terkonversi menjadi nilai intensitas. Partikel muon karena massanya yang besar dapat melewati beberapa piksel tanpa terganggu, sehingga meninggalkan jejak berupa track yaitu beberapa piksel yang membentuk garis lurus. Partikel elektron akan terbelokkan arahnya ketika mengalami hamburan, karena massanya yang kecil. Karena itu elektron akan meninggalkan jejak berupa worm yaitu beberapa piksel yang tidak membentuk garis lurus.

Tujuan dari penelitian ini adalah mempelajari kinerja penggunaan webcam sebagai alat detektor sinar kosmik. Peneilitian ini mencakup karakteristik noise serta sinyal yang tertinggal pada sensor. Memepelajari kategori gambar yang dihasilkan oleh kamera, serta memperoleh besaran fluks sinar kosmik untuk dibandingkan dengan referensi standar. Hasil penelitian akan dijadikan acuan untuk pengembangan penelitian selanjutnya di bidang pendeteksian radiasi partikel subatomic.

\section{Metode Penelitian}

Pendeteksian partikel dalam penelitian ini menggunakan webcam komersil bermerk Logitech tipe 260. Lensa pada webcam tersebut dilepas untuk mengurangi interaksi partikel dengan materi sebelum melewati detektor. Selain itu juga terdapat komponen lampu LED yang juga dilepas. Di atas sensor CMOS terdapat plastik yang menempel yang berfungsi sebagai filter pembeda warna untuk sumber cahaya tampak. Sangat dimungkinkan bahwa partikel alfa tidak dapat menembus lapisan plastik tersebut sehingga tidak dapat dideteksi oleh sensor. Sensor kemudian ditutup 
menggunakan aluminium foil dan selotip hitam, untuk menghalangi cahaya tampak memasuki sensor.

Webcam kemudian dihubungkan dengan perangkat komputer, dimana operasi serta peyimpanan hasil gambar webcam dijalankan melalui perangkat lunak dalam bahas python, memanfaatkan modul pengolah gambar open CV. Hasil yang didapat adalah berupa gambar hitam putih berukuran 480 × 640 piksel, dimana pada setiap piksel terdapat besaran intensitas yang akan menentukan kecerahan warna pada piksel tersebut. Webcam secara efektif (ditambah waktu operasi program) akan mengambil gambar pada kecepatan 15 fps.

Untuk mendapatkan data noise, disimpan gambar di setiap interval waktu tertentu. Dari data noise, didapatkan informasi berupa piksel hangat, yaitu piksel pada sensor yang memiliki probabilitas tinggi sebagai sumber noise, serta informasi berupa batas intensitas untuk penentuan sinyal. Kemudian dalam pemgukuran sinyal, disimpan gambar yang memenuhi kriteria sinyal yang sudah ditentukan. Tentunya sinyal akan terekam bila partikel melewati sensor tepat ketika kondisi webcam sedang mengambil frame tersebut.

Pengambilan data baik noise maupun sinyal masing - masing dilakukan selama 60 jam di meja kerja dalam gedung Departemen Fisika kampus Universitas Padjadjaran Jatinangor.

\section{Hasil dan Pembahasan}

Lokasi piksel hangat diperoleh dari melihat frekuensi seringnya sebuah piksel menghasilkan suatu intensitas. Di bawah ini adalah tabel banyaknya setiap piksel menghasilkan intensitas lebih dari nol, dari total pengambilan 20.000 buah gambar. Ciri - ciri dari warm piksel adalah bahwa piksel tersebut memberikan luaran intensitas jauh lebih sering dibanding lokasi piksel lainnya. Beberapa piksel hangat berlokasi berdekatan sehingga membentuk sebuah klaster. Piksel hangat yang terindikasi terdapat pada sensor dapat dilihat di Tabel 1 .

Tabel 1. Frekuensi pembacaan per piksel dari pengukuran noise sebanyak 20.000 pengambilan gambar. Nomor 1 hingga 3 adalah lokasi piksel hangat

\begin{tabular}{|c|c|c|c|}
\hline No. & \multicolumn{2}{|c|}{$\begin{array}{l}\text { Lokasi/Jumlah } \\
\text { Piksel/Klaster }\end{array}$} & $\begin{array}{l}\text { Frekuensi } \\
\text { Pembacaan }\end{array}$ \\
\hline \multirow{2}{*}{1.} & 200,338 & 200,339 & \multirow{2}{*}{1601} \\
\hline & 201,338 & 201,339 & \\
\hline \multirow{2}{*}{2.} & 280,534 & 280,535 & \multirow{2}{*}{752} \\
\hline & 281,534 & 281,535 & \\
\hline 3. & \multicolumn{2}{|c|}{479,582} & 627 \\
\hline
\end{tabular}




\begin{tabular}{|c|c|c|c|}
\hline \multirow{2}{*}{4.} & 200,336 & 200,337 & \multirow{2}{*}{20} \\
\hline & 201,336 & 201,337 & \\
\hline 5. & \multicolumn{2}{|c|}{280,533} & 9 \\
\hline 6. & \multicolumn{2}{|c|}{0,152} & 4 \\
\hline 7. & \multicolumn{2}{|c|}{16 piksel (4 klaster) } & 3 \\
\hline 8. & 445,638 & 445,639 & 2 \\
\hline 9. & \multicolumn{2}{|c|}{174 piksel } & 1 \\
\hline 10. & \multicolumn{2}{|c|}{306.993 piksel } & 0 \\
\hline
\end{tabular}

Selama pengambilan sebanyak 20.000 gambar background, 306.993 buah piksel selalu menghasilkan intensitas nol. Sedangkan sebanyak 207 buah piksel menghasilkan intensitas tidak nol, secara keseluruhan sebanyak 3019 kali, atau rata - rata 15 kali masing - masing pikselnya. Didapatkan persentase munculnya noise yang sangat kecil yaitu dalam orde $10^{-5} \%$.

Kluster/piksel pada nomor 1-3 pada tabel di atas diindikasi sebagai piksel hangat. Piksel - piksel hangat tersebut kemudian dihilangkan untuk tahap analisa yang selanjutnya. Akumulasi keseluruhan noise dari pengambilan 20.000 gambar ditunjukkan pada Gambar 1 di bawah.

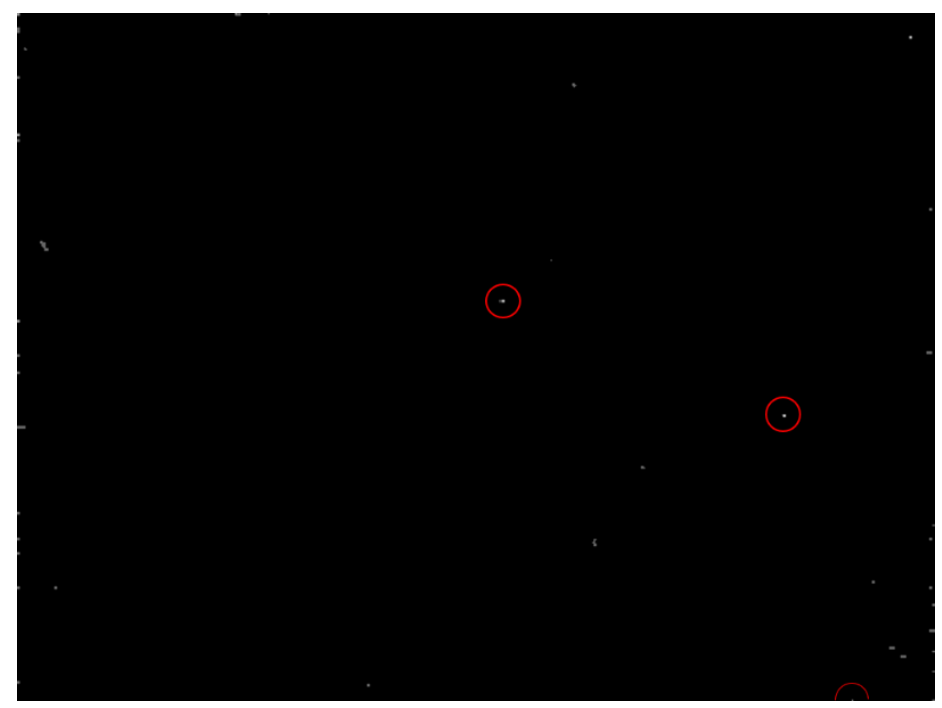

Gambar 1. Akumulasi 20.000 gambar background. Lingkaran merah menunjukkan lokasi piksel hangat.

Data background atau noise digunakan untuk menentukan kriteria sinyal, yaitu apakah suatu frame gambar yang tidak nol dihasilkan oleh partikel yang melewati sensor, ataukah hanya noise dari sensor itu sendiri. Besaran yang dapat digunakan sebagai kriteria dapat berupa intensitas total dari frame gambar ( $\left.i_{\text {tot }}\right)$, atau intensitas 
maksimum dalam sebuah frame gambar $\left(i_{\max }\right)$. Pada Gambar 2 adalah plot $i_{\text {tot }}$ terhadap $i_{\max }$ untuk seluruh frame background.

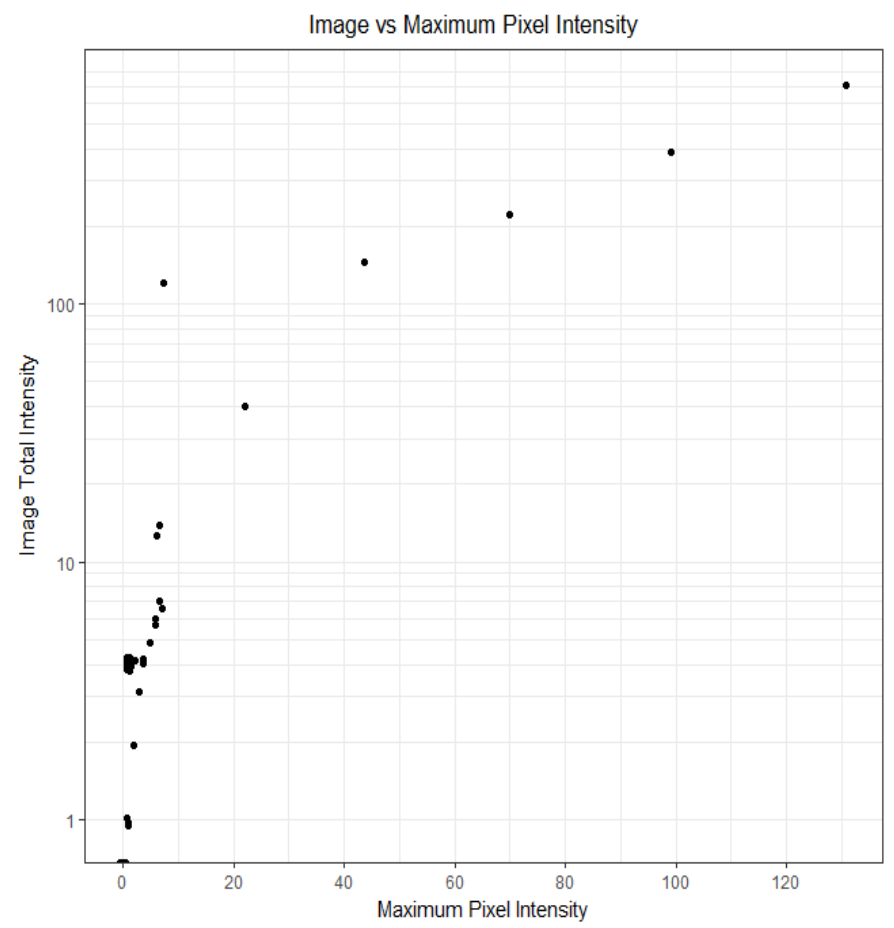

Gambar 2. Plot intensitas total gambar (skala log) terhadap intensitas piksel maksimum, untuk seluruh data gambar background.

Seluruh frame gambar pada pengukuran background berada pada wilayah $i_{\text {tot }}<15$ dan $\mathrm{i}_{\max }<10$, kecuali 6 buah piksel. Dari 6 buah piksel yang berada di luar wilayah background, 5 diantaranya ditemukan adalah sinyal, sedangkan 1 gambar adalah hasil dari noise. 1 gambar noise tersebut memiliki $i_{\text {tot }}=117$ dan $i_{\max }=7$. Disimpulkan bahwa memberikan batasan pada $i_{\max }$ merupakan kriteria yang lebih kuat dibandingkan bila menggunakan $i_{\text {tot }}$.

\subsection{Sinyal Partikel}

Pengambilan data dengan menggunakan kriteria $i_{\max }>20$ dilakukan selama kurang lebih 60 jam, dan diperoleh sinyal sebanyak 553 buah frame. Seperti yang diperoleh pada pengukuran sebelumnya [4], dalam eksperimen ini juga diperoleh tipe gambar spot, track, dan worm, seperti ditunjukkan pada Gambar 3. Diasumsikan bahwa jenis partikel track dihasilkan oleh muon kosmik, dimana karena massanya yang besar, muon dapat mengionisasi elektron tanpa terhamburkan, sehingga dapat melewati beberapa piksel dengan lintasan yang lurus.

Dari setiap frame gambar sinyal, dilakukan cropping yaitu pengambilan gambar hanya pada bagian yang terdapat sinyal. Cropping dilakukan hingga terbentuk frame berukuran 20x20 piksel. Gambar - gambar tersebut hanya memiliki informasi intensitas sinyal partikel dan bersih dari noise. Histogram intensitas total dari setiap gambar sinyal setelah cropping ditunjukkan pada Gambar 4 


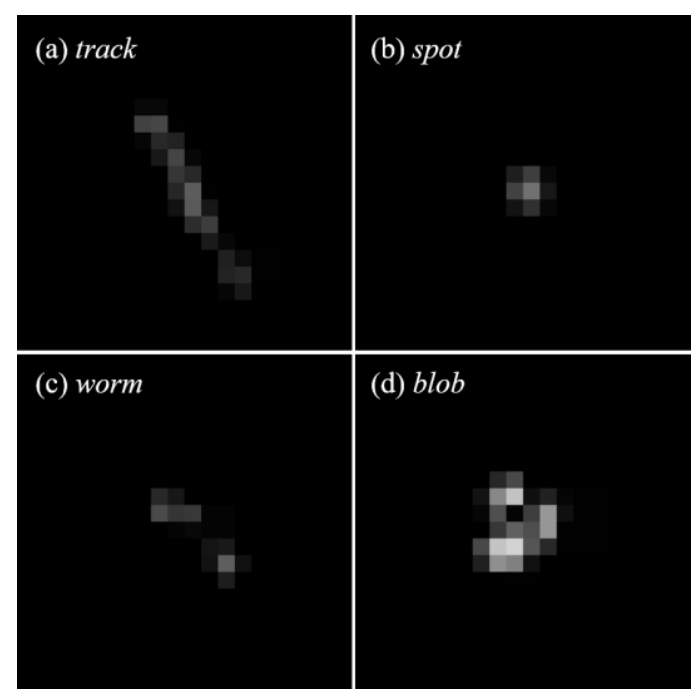

Gambar 3. Jenis - jenis gambar yang dihasilkan oleh partikel yang melewati sensor CMOS.

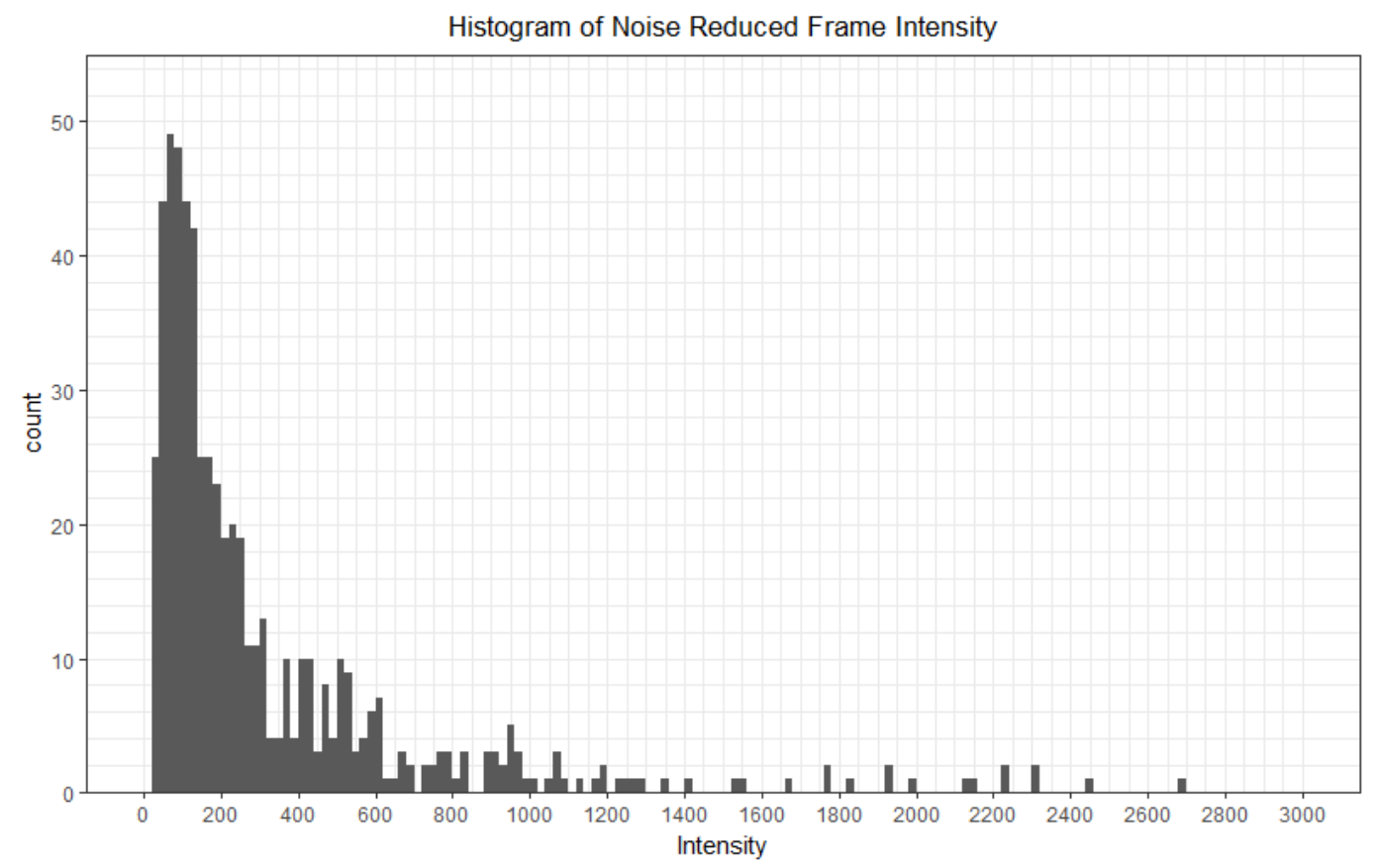

Gambar 4. Histogram Intensitas Klaster Sinyal.

Diasumsikan bahwa besar intensitas gambar sinyal sebanding dengan energi partikel yang diserap oleh sensor [3]. Karena dimensi sensor yang sangat kecil hanya sedikit bagian energi sinar kosmik yang tertinggal pada sensor. Karena itu histogram intensitas tidak bisa langsung diasosiasikan dengan energi sinar kosmik. Hasil bahwa histogram intensitas sinyal mengalami penurunan sesuai dengan pengamatan bahwa energi sinar kosmik juga bersifat menurun mengikuti fungsi pangkat (power-law function) [1].

Fluks (laju kejadian setiap menit dan setiap $\mathrm{cm}^{2}$ ) sinar kosmik dihitung dari banyaknya kejadian dibagi total waktu pengamatan dan luas sensor, yaitu: 


$$
\text { Fluks }=\frac{553 \text { kejadian }}{(4051 \text { menit }) \times\left(0,095 \mathrm{~cm}^{2}\right)}=1,4 \mathrm{kejadian} /\left(\mathrm{men} \cdot \mathrm{cm}^{2}\right)
$$

Hasil nilai fluks tersebut dalam berada dalam orde yang sama dengan nilai referensi rata - rata fluks sinar kosmik di permukaan bumi yaitu $1 \frac{\mathrm{kejadian}}{\mathrm{men} \cdot \mathrm{cm}^{2}}$ [2].

Dari hasil pengukuran background diperoleh bahwa tingkat noise pada perangkat webcam di eksperimen ini sangatlah kecil. Bahkan dengan adanya piksel hangat, piksel - piksel hangat tersebut hanya menyala sebanyak kurang lebih 1600 kali dari 20.000 pengambilan gambar. Akan tetapi ketika dilakukan pengukuran noise, beberapa piksel hangat muncul jauh lebih sering dibanding presentase di atas. Karena itu meskipun tingkat noise sangat kecil, masih perlu dibuat kriteria sinyal, untuk lebih memastikan lagi validitas sinyal yang tertangkap.

Dari hasil pengukuran sinyal, terdapat beberapa kategori gambar yang tertangkap. Analisa bentuk gambar akan sangat berguna salah satunya untuk dapat mengetahui lintasan yang dilewati muon. Di dalam penelitian ini tidak dilakukan analisa bentuk gambar.

Spektrum intensitas klaster menunjukkan sifat yang menurun sama dengan spektrum energi sinar kosmik. Intensitas klaster diasumsikan sebanding dengan besar kehilangan energi yang dialami sinar kosmik ketika melewati sensor.

\section{Kesimpulan}

Di dalam penelitian ini telah dilakukan pendeteksian sinar kosmik menggunakan webcam komersil. Hasil dari penelitian adalah bahwa webcam komersil dapat mendeteksi adanya radiasi partikel yang melewatinya dengan menghasilkan bercak gambar berukuran kurang dari 20x20 piksel, setelah dibedakan dengan gambar hasil noise. Terdapat tiga bentuk gambar utama yaitu track, spot dan worm, serta bentuk lain seperti big blob. Fluks pendeteksian sinar kosmik terukur adalah 1,4 $\frac{\text { kejadian }}{\text { menit } \cdot \mathrm{cm}^{2}}$, yaitu dalam orde yang sama dengan nilai referensi standar.

\section{Daftar Pustaka}

1. T. K. Gaisser, R. Engel, E. Resconi, Cosmic rays and particle physics, Cambridge University Press (2016).

2. K. Nakamura, Review of Particle Physics J. Phys. G: Nucl. Part. Phys. Vol. 37 075021 (2010).

3. L. Servoli et al 2010 Characterization of standard CMOS pixel imagers as ionizing radiation detectors J. Instrum. Vol. 5 No. 07 (2010) p. 07003.

4. D. Groom, Cosmic rays and other nonsense in astronomical CCD imagers Exp Astron Vol. 14 No. 1 (2002) p. 45-55.

5. J. Vandenbroucke et al, Measurement of cosmic-ray muons with the Distributed Electronic Cosmic-ray Observatory, a network of smartphones JINST Vol. 11 (2016) p. 04019. 
6. M. Perez et al 2016 Particle detection and classification using commercial off the shelf CMOS image sensors Nucl. Instrum. Methods Phys. Res. Sect. A: Accel. Spectrom. Detect. Assoc. Equip., 827 171-180. 